Sharif University of Technology
Scientia Iranica
Transactions E: Industrial Engineering
SCIENTIA
I RAN I C A

\title{
Game-theoretic analysis of coordinating pricing and marketing decisions in a multi-product multi-echelon supply chain
}

\author{
A. Naimi Sadigh, S. Kamal Chaharsooghi* and M. Sheikhmohammady \\ Department of Industrial Engineering, Faculty of Engineering, Tarbiat Modares University, Tehran, Iran.
}

Received 18 October 2014; received in revised form 10 January 2015; accepted 20 April 2015

KEYWORDS
Pricing;
Marketing;
Inventory
management;
Game theory;
Multi-product;
Multi-echelon supply
chain.

KEYWORDS

\begin{abstract}
Supply chain coordination aims at improving supply chain performance by aligning the decisions and the objectives of individual firms. Supply chain participants can cooperate for different decisions such as pricing, inventory management, and marketing to gain more profit. The current research considers coordination of these decisions in a multiproduct multi-echelon supply chain composed of multiple suppliers, single manufacturer, and multiple retailers. It is assumed that the demand of each product is non-linearly influenced by retailing price and marketing expenditure. Since all the supply chain members possess equal power in the market and make their decisions simultaneously, the threeechelon supply chain problem is a non-cooperative Nash game. In order to find the Nash equilibrium, we formulate a Non-linear Complementarity Problem (NCP) based on the optimality conditions, and also an iterative algorithm is proposed to solve largesize instances. Finally, a numerical example is presented and a comprehensive sensitivity analysis is conducted to discuss important managerial insights.
\end{abstract}

(C) 2016 Sharif University of Technology. All rights reserved.

\section{Introduction}

A supply chain is a system of different firms involved in moving materials and products from suppliers to customers. In three-echelon supply chains, there are multiple suppliers that provide raw materials to manufacturers, the manufacturers produce products for retailers, and the retailers sell final products to customers. Coordination is an appropriate mechanism in a decentralized supply chain in order to align the objectives of different supply chain members with the goal of improving supply chain performance. Some of the most important coordination mechanisms are pricing, marketing, and production decisions $[1,2]$

\footnotetext{
*. Corresponding author. Tel.: +982182883345

E-mail addresses: naimi@irandoc.ac.ir (A. Naimi Sadigh);

skch@modares.ac.ir (S.K. Chaharsooghi);

msheikhm@modares.ac.ir (M. Sheikhmohammady)
}

which are investigated in the current research. In real world, supply chains mostly provide multiple types of products in order to fulfill different customer demands.

In this paper, we address a competitive threeechelon supply chain, in which there are multiple retailers who sell different products to the end consumers and spend money for marketing purposes. On the second echelon, there is a manufacturer who produces all types of products in a common production interval and presents them to the retailers at a wholesale price. The manufacturer requires several raw materials which are purchased from several competing suppliers. In the upstream, there are multiple suppliers who compete to obtain more market share of raw materials needed by the manufacturer. Therefore, we investigate a threeechelon decentralized model with pricing decisions in each echelon. The main purpose of this paper is to investigate the coordination of three major decisions 
of supply chain members: pricing, marketing, and inventory management in a three-echelon supply chain consisting of multiple suppliers, one manufacturer, and multiple retailers. Since all the supply chain members possess equal power and determine their strategies simultaneously, we formulate the model as a Nash game in which each player aims to maximize its own profit with regard to the actions selected by the other members. We propose an iterative solution approach to find the equilibrium point of the multi-echelon Nash game with high precision in large-size problem instances. Furthermore, we formulate the KarushKuhn-Tuker (KKT) optimality conditions of the Nash game as Non-linear Complementarity Problem (NCP) as an alternative approach.

The reminder of this paper is structured as follows. The relevant research is reviewed in Section 2. Section 3 is devoted to problem description and mathematical formulation. In Section 4, we propose an iterative solution approach and NCP formulation. A numerical example with a comprehensive sensitivity analysis is discussed in Section 5. The final section includes the concluding remarks and presents several extensions for consideration in future research.

\section{Literature review}

Lack of coordination can lead to poor performance of supply chain, such as high inventory cost, improper utilization of production capacity, and low customer satisfactory [3]. Thereby, some research has studied channel coordination from different perspectives of business decisions, including pricing, marketing expenditure, production, and inventory decisions. However, there are a few studies which have considered more than one aspect of coordination. For a comprehensive review on channel coordination, refer to [4].

\subsection{Coordination of inventory and pricing models}

Many researchers have investigated pricing and inventory coordination in supply chains. Goyal [5] presented integrated models for an inventory system in which the manufacturer made all replenishment decisions for its retailers to minimize the joint inventory cost. Tersine and Price [6], Martin [7], and Abad [8] proved that the retailer(s) could achieve more profits when coordinating the price and order quantity decisions in various environments. Yu et al. [9], SeyedEsfahani et al. [10], and Esmaeili and Zeephongeskul [11] studied joint pricing and order inventory problem for profit optimization with pricedependent demand in a two-echelon supply chain. They showed that the supply chain members could obtain more profit in comparison with the situation in which they made decisions individually. Wu and
Zhao [12] developed an EOQ model for deteriorating products with linearly increasing time-varying demand under trade credit and presented an efficient solution algorithm to solve the optimal replenishment cycle.

Multi-product supply chains are more complicated due to limited production capacity and customer needs [13]. The impact of product variation on supply chain performance has been studied by Thonemann and Bradley [14]. Song and Xue [15] investigated pricing problem of multiple products in dynamic inventory environment with backlogging. They developed an algorithm to compute the optimal solutions. Zhu and Thonemann [16] and Dong et al. [17] studied a two-product joint pricing and inventory management problem in which substitution effect of products was included to improve the profit relative to the two independent products. Maihami and Karimi [18] considered the problem of replenishment policy and pricing decisions for non-instantaneous deteriorating products subject to promotional effort. Hsieh et al. [19] considered multiple manufacturers and a common retailer with substitutable product sold through the common retailer and the direct channels under decentralized and centralized conditions.

The abovementioned research considered only coordination of pricing and inventory management in a two-echelon supply chain channel where manufacturer(s) and retailer(s) made their decisions. However, they have not investigated suppliers' echelon.

\subsection{Advertising models}

Advertisement in supply chain is used to encourage, persuade, or manipulate a customer in order to increase the demand. Cooperative advertising is a financial agreement where a manufacturer offers to share a specific percentage of his retailer's marketing expenditures. Many researchers including Karray [20], Kunter [21], and Zhang et al. [22] have studied the static models that consist of one retailer. Aust and Buscher [23] proposed a vertical cooperative advertising model for duopolistic channel, consisting of multiple retailers and a single manufacturer. Moreover, Sayadi and Makui [24] proposed advertising decisions for both retail and online channels with one retailer and one manufacturer and analyzed the model through a differential game theory approach.

Another main criterion of mathematical formulations in this field is the demand function. Concerning the mathematical modeling of advertising costs, it is obvious that a linear integration is generally used in terms of advertising expenditures [25,26], while nonlinear advertising expenditures are rare [27,28]. However, as in previous subsection, all the articles reviewed above have studied advertising decisions considering duopolistic market. 


\subsection{Nash equilibrium for supply chain games}

In order to study the independence of supply chain members, each member tries to improve its own profit. Non-cooperative game mechanism, especially Nash equilibrium concept, is mostly used to devise different decisions of supply chain members in many articles. Nash equilibrium is one of the most famous noncooperative solution concepts [29]. Hafezalkotob and Makui [30] studied a two-echelon supply chain with one manufacturer and several retailers, in which the manufacturer selected a set of retailers. Each retailer determined order quantity considering transportation and inventory cost, and the manufacturer optimized its wholesale price.

Qin et al. [31] stashed equilibrium in a twoechelon supply chain considering inventory decisions based on classic EOQ models which are much common in the field. Caldentey and Wein [32] studied Nash equilibrium in a non-cooperative game in a supply chain, where there were a manufacturer and several retailers. They focused on how to use linear transfer payments to obtain the optimal profit of the supply chain. Dumrongsiri et al. [33] proposed models in which the customers' demands were sensitive to the price and service quality. Nash equilibrium has also been used by Cai et al. [34] to study the impact of price discount contracts in different scenarios and compared with some other games. They have demonstrated that the price discount contracts outperform the non-contract scenarios. Yue and You [35] proposed a three-echelon supply chain in which there was single leader and multiple followers. The multiple followers competed with each other under the Nash equilibrium assumptions. Hoseininia et al. [36] investigated an inventory management model in a multichannel distribution system including single manufacturer and several retailers with stochastic demand. They proved the existence of Nash equilibrium using parameter restriction, which implied its uniqueness.

Despite the fact that in real-world problems, members in different echelons of a supply chain compete with regard to prices, Aust and Buscher [37] mention that there are a few research works which have considered multi-echelon supply chains with pricing decisions in each echelon. Naimi Sadigh et al. [38] investigated a mixed integer pricing game in a multiechelon supply chain in which the retailers determined order frequency as an integer number. However, the model can converge in very restrictive conditions and their proposed approach is not able to find an equilibrium point when the number of products or retailers increase. The proposed model and solution approach of this paper can tackle large-size problems and find the equilibrium of the multi-echelon with precision.

\section{Problem description}

The problem of this study is a three-echelon supply chain including multiple suppliers, single manufacturer, and multiple retailers. The suppliers sell multiple raw materials to the manufacturer; then, the manufacturer wholesales multiple products to the retailers who finally sell products to end customers.

\subsection{Notations and assumptions}

The proposed model in this paper is identified by the following assumptions:

1. The channel includes one manufacturer, multiple suppliers, and multiple retailers;

2. The manufacturer's production capacity for multiple products is assumed to be limited;

3. The suppliers' capacities for providing raw materials are restricted;

4. The retailers are independent of each other and have their own individual markets;

5. Each retailer's demand decreases with respect to his retail price and increases with respect to marketing expenditure $[11,39]$;

6. Shortage is not permitted. Therefore, the production rate is greater than demand rate [40];

7. All parameters of supply chain members are deterministic and known in advance [9];

8. There are at least two suppliers who are responsible for each raw material of each product of the manufacturer. In other words, since we consider competition among suppliers, single sourcing is not permitted [41].

The relevant parameters and decision variables of supply chain members are defined in Tables 1 and 2 based on Naimi Sadigh et al. [38], respectively.

This paper is a generalization of the mathematical model in Naimi Sadigh et al. [38], which is able to find the Nash equilibrium in the large-size problems. In fact, in the current research, the manufacturer determines the ordering decisions of each product for the retailers based on its common cycle interval. Figure 1 illustrates relations among the supply chain members in the problem of study and shows decision variables of each echelon.

\subsection{The retailers' model formulation}

In this paper, we consider demand of each product as a function of retail price, and marketing expenditure, such that demand increases with decrease in the retail price or increase in the marketing expenditure. Therefore, the demand function, which is non-linear, is as follows $[27,39]$ :

$$
D\left(p_{i t}, m_{i r}\right)=f_{i r} p_{i r}^{-\alpha_{i r}} m_{i r}^{\beta_{i r}},
$$


Table 1. Parameters of the suppliers, manufacturer, and retailers.

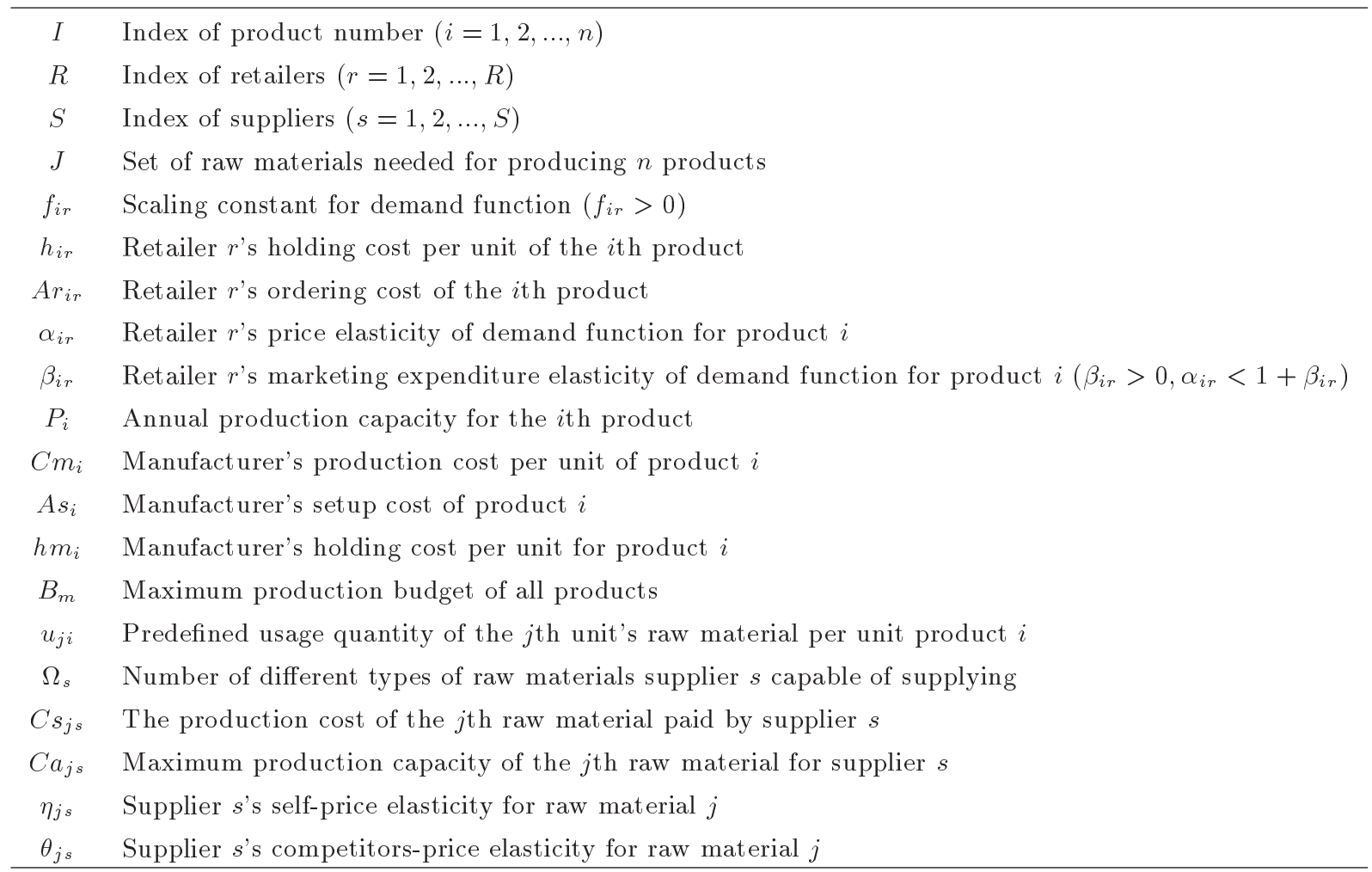

Table 2. Variables of the suppliers, manufacturer, and retailers.

\begin{tabular}{cl}
\hline$p_{i r}$ & Retailing price of the $r$ th retailer for product $i$ \\
$m_{i r}$ & Marketing expenditure of the $r$ th retailer for product $i$ \\
$T$ & Common production interval \\
$\psi_{i}$ & The unit wholesale price of product $i$ \\
$Q_{j}$ & The required quantity of the $j$ th raw material to produce all products \\
$F_{j s}$ & The price of the $j$ th raw material charged by the supplier $s$ to the manufacturer \\
$v_{j s}$ & The quantity of the $j$ th raw material produced by supplier $s$ \\
$D\left(p_{i r}, m_{i r}\right)$ & The demand of the $r$ th retailer for product $i$
\end{tabular}

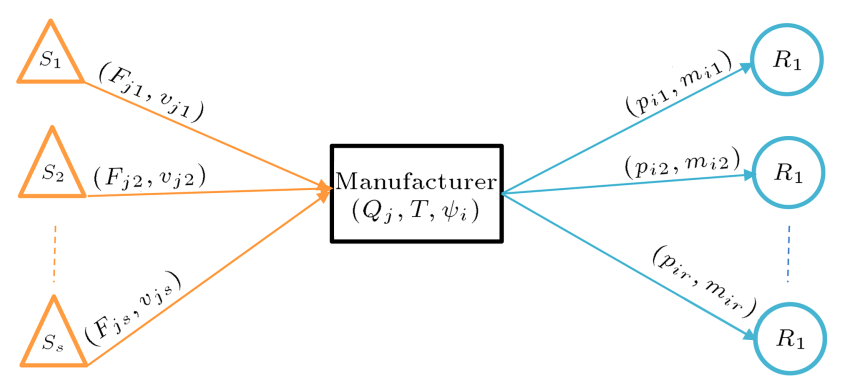

Figure 1. Scheme of a three-echelon supply chain.

where $f_{\text {ir }}$ is a positive scaling constant. The price elasticity and marketing expenditure elasticity of demand for each product are shown by $\alpha_{i r}$ and $\beta_{i r}$, respectively.

Decision variables of each retailer are retail price and marketing expenditure of each product. So, these decision variables are known as strategy set of each retailer. The main objective of each retailer is to maximize his profit by determining his strategy set. Thus, the net profit of each retailer can be obtained through the following equation:

$$
\begin{aligned}
& \operatorname{Max} \Pi R_{r}\left(p_{i r}, m_{i r}\right)=\sum_{i=1}^{n} p_{i r} D_{i r}-\sum_{i=1}^{n} \psi_{i} D_{i r} \\
& -\sum_{i=1}^{n} m_{i r} D_{i r}-\frac{T}{2} \sum_{i=1}^{n} D_{i r} h_{i r}-\sum_{i=1}^{n} \frac{A r_{i r}}{T}
\end{aligned}
$$

S.t. $m_{i r}, p_{i r} \geq 0$.

The first term in Eq. (2) is the total sales revenue of products, and the total purchasing cost from the manufacturer and total marketing expenditure cost are included in the second and third terms, respectively. 
The annual inventory holding and ordering costs are calculated regarding the common production interval of manufacturer $(T)$ as, respectively, shown in the fourth and fifth terms of the objective function. Constraint (3) ensures non-negativity of the retailing price and marketing expenditure of each product.

\subsection{The manufacturer's model formulation}

We consider that the manufacturer's decision variables include unit wholesale price, $\psi_{i}$, for each product, the common production interval, $T$, and the quantity of required raw materials, $Q_{j}$. These decision variables are the strategy set of manufacturer. The manufacturer's profit equals the wholesales revenue minus the production cost, purchasing cost, and setup and holding costs. Thus, the manufacturer's objective function can be written as follows:

$$
\begin{gathered}
\operatorname{Max}_{M}\left(\psi_{i}, T, Q_{j}\right)=\sum_{i=1}^{n} \psi_{i} \sum_{r=1}^{R} D_{i r}-\sum_{i=1}^{n} C m_{i} \sum_{r=1}^{R} D_{i r} \\
\quad-\sum_{j=1}^{J} \sum_{s=1}^{S} F_{j s} v_{j s}-\frac{\sum_{i=1}^{n} A s_{i}}{T} \\
\quad-\frac{T}{2} \sum_{=1}^{n} h m_{i} \sum_{r=1}^{R} D_{i r}\left(\frac{\sum_{r=1}^{R} D_{i r}}{P_{i}}\right) \\
\text { S.t. } T \sum_{i=1}^{n} C m_{i} \sum_{r=1}^{R} D_{i r} \leq B_{m}, \\
Q_{j}=u_{j i}\left(\sum_{r=1}^{R} D_{i r}\right) \\
\quad \text { for } i=1,2, \ldots, n \& j=1,2, \ldots, J \\
\psi_{i} \geq 0, T>0, Q_{j} \geq 0 .
\end{gathered}
$$

Since shortage is not permitted for the manufacturer, the production rate must be at least equal to the expected demand rate $\left(P_{i} \geq \sum_{r=1}^{R} D_{i r}\right)$. In such a multiproduct manufacturing system, if $\sum_{i=1}^{n} \frac{\sum_{r=1}^{R} D_{i r}}{P_{i}} \leq 1$, then there is certainly a feasible time interval $\bar{T}$ in which all the products can be produced. Constraint (5) states the manufacturer budget for production of all products. Constraint (6) ensures that the quantity of required raw materials is satisfied such that all demands of retailers are covered for each product. The decision variables' range can be stated as Constraint (7).

\subsection{The suppliers' model formulation}

The decisions variables that must be determined by each supplier are pricing decisions for the raw materials and the quantity of raw materials that are needed to be produced for the manufacturer. So, the strategy set of each supplier includes the set of these decision variables. Suppliers must determine their optimal strategies, simultaneously, in order to maximize their net profits. Each supplier faces production cost of raw materials to provide requirement of the manufacturer and the sales revenue of suppliers can be obtained through selling the raw materials to the manufacturer. Therefore, the mathematical model of each supplier can be stated as follows:

$$
\begin{aligned}
& \operatorname{Max} \Pi S_{s}\left(F_{j s}, v_{j s}\right)=\sum_{j=1}^{J} F_{j s} v_{j s}-\sum_{j=1}^{J} C s_{j s} v_{j s}, \\
& \text { S.t. } v_{j s}=Q_{j}-\eta_{j s} F_{j s}+\sum_{s=1 / s}^{s} \theta_{j s} F_{j s}, \\
& \sum_{s=1}^{s} v_{j s}=Q_{j} \text { for } j=1,2, \ldots, J \\
& v_{j s} \geq 0, F_{j s} \geq 0 .
\end{aligned}
$$

Constraint (9) shows that the demand of each raw material depends on both self-offered price of the raw materials and the other suppliers' offered prices. In other words, in order to gain more market share from the manufacturer, the suppliers compete not only with the manufacturer, but also compete with each other. Constraint (10) guarantees that the quantity of raw materials needed by the manufacturer is certainly provided by the set of suppliers. This constraint is a joint constraint and it is common for all suppliers that can produce the $j$ th raw material. Thereby, in the suppliers' echelon, we face a Generalized Nash Equilibrium Problem (GNEP). Finally, Constraint (11) ensures that the value of the decision variables is nonnegative.

\section{Solution approach}

Combining the three echelons formulations mentioned in the previous section results in a non-cooperative Nash game model with $S+1+R$ players including $S$ suppliers, one manufacturer, and $R$ retailers. In order to solve the multi-echelon Nash game resulting from the combination of $S$ suppliers, one manufacturer, and $R$ retailers' sub models, we first analyze the optimality conditions of each player sub-problem. Then, we calculate the Nash equilibrium set of strategies by integrating the optimality conditions of all players in the form of NCP.

\subsection{The NCP formulation}

First, we need to search the best responses of the retailers, the manufacturer, and the suppliers according to the given strategies of the other players. 
The best response of each retailer can be calculated by optimizing that retailer's sub-model while the manufacturer's strategies (i.e., $\psi_{j}, T, Q_{j}$ ) are given. Since the benefit function of the retailers is pseudoconcave (see Appendix A for proof), one can apply the first-order optimality conditions to derive the best reactions (i.e., $p_{i r}^{*}, m_{i r}^{*}$ ) of the retailers.

The retailers' sub-models are unconstraint problems; hence, we can write the optimal strategies, which are obtained when the first derivatives of Eq. (2) vanish:

$$
\begin{aligned}
& \frac{\partial \Pi R_{r}}{\partial p_{i r}}=\left(\alpha_{i r}-1\right) p_{i r}-\alpha_{i r}\left(m_{i r}+\psi_{i}+T h_{i r} / 2\right)=0, \\
& \frac{\partial \Pi R_{r}}{\partial m_{i r}}=\left(\beta_{i r}-1\right) m_{i r}-\beta_{i r}\left(p_{i r}-\psi_{i}-\frac{T h_{i r}}{2}\right)=0 .
\end{aligned}
$$

By concatenating on Eqs. (12) and (13), we have:

$$
p_{i r}^{*}=\frac{\alpha_{i r}\left(\psi_{i}+T h_{i r} / 2\right)}{\alpha_{i r}-\beta_{i r}-1},
$$

and:

$$
m_{i r}^{*}=\frac{\beta_{i r}\left(\psi_{i}+T h_{i r} / 2\right)}{\alpha_{i r}-\beta_{i r}-1} .
$$

On the second echelon, the best response of the manufacturer can be obtained by optimizing the manufacturer's sub-model while the retailers' actions (i.e., $\left.p_{i r}, m_{i r}\right)$ are known as well as the suppliers' (i.e. $\left.F_{j s}, v_{j s}\right)$. Since the sub-model of the manufacturer is convex with regard to its strategies (see Appendix B for the proof), we can apply the KKT optimality conditions to drive the best reactions of the manufacturer. The KKT identity and the complementarity slackness are achieved through Eqs. (16) to (19):

$$
\begin{aligned}
& L_{M}\left(\psi_{i}, T, Q_{j}\right)=\sum_{i=1}^{n} \psi_{i} \sum_{r=1}^{R} D_{i r}-\sum_{i=1}^{n} C m_{i} \sum_{r=1}^{R} D_{i r} \\
&-\sum_{j=1}^{J} \sum_{s=1}^{S} F_{j s} v_{j s}-\frac{\sum_{i=1}^{n} A s_{i}}{T} \\
&-\frac{T}{2} \sum_{i=1}^{n} h m_{i} \sum_{r=1}^{R} D_{i r}\left(\frac{\sum_{r=1}^{R} D_{i r}}{P_{i}}\right) \\
&-\lambda\left(\sum_{i=1}^{n} C m_{i} \sum_{r=1}^{R} D_{i r}-B_{m}\right), \\
& \frac{\partial L_{M}}{\partial T}=\left(1 / 2 \sum_{i=1}^{n} \sum_{r=1}^{R} h m_{i} D_{i r}\left(\frac{\sum_{r=1}^{R} D_{i r}}{P_{i}}\right)\right. \\
&\left.+\lambda \sum_{i=1}^{n} C m_{i} \sum_{r=1}^{R} D_{i r}\right) T^{2}-\sum_{i=1}^{n} A s_{i}=0,
\end{aligned}
$$

$$
\begin{aligned}
& \frac{\partial L_{M}}{\partial T}=\sum_{r=1}^{R} D_{i r} \\
& \lambda .\left(T \sum_{i=1}^{n} C m_{i} \sum_{r=1}^{R} D_{i r}-B_{m}\right)=0 .
\end{aligned}
$$

According to Eq. (17), it is inferred that:

$T^{*}=$

$$
\sqrt{\frac{\sum_{i=1}^{n} A s_{i}}{0.5 \sum_{i=1}^{n} h m_{i} \sum_{r=1}^{R} D_{i r}\left(\frac{\sum_{r=1}^{R} D_{i r}}{P_{i}}\right)+\lambda \sum_{i=1}^{n} C m_{i} \sum_{r=1}^{R} D_{i r}}}
$$

However, Eq. (18) shows that the derivative of the Lagrange Function cannot be equal to zero. Since the benefit function of the manufacturer increases with $\psi_{i}$, it can be easily concluded that the best $\psi_{i}$ is obtained when the retailers choose the highest possible price for each product. Using a similar approach with Esmaeili et al. [27], we consider the breakeven point of the manufacturer as an initial value for the wholesale price of each product $\psi_{i}^{0}$ as follows:

$$
\begin{aligned}
\psi_{i}^{0}= & C m_{i}+\frac{1}{\sum_{r=1}^{R} D_{i r}}\left(\frac{\sum_{i=1}^{n} A s_{i}}{T}\right. \\
& +\frac{T}{2} \cdot \sum_{i=1}^{n} h m_{i} \sum_{r=1}^{R} D_{i r}\left(\frac{\sum_{r=1}^{R} D_{i r}}{P_{i}}\right) \\
& \left.+\sum_{j=1}^{J} \sum_{s=1}^{s} F_{j s} v_{j s}\right) .
\end{aligned}
$$

Then, we assume that the optimal wholesale price is a positive coefficient $C_{i}>1$ of this breakeven price (i.e., $\left.\psi_{i}^{*}=C_{i} \psi_{i}^{0}\right)$. The most appropriate $C_{i}$ can be gained through a sensitivity approach (see Section 5.2). Having known the retailers' strategies, the value of $Q_{j}$ can be achieved from Eq. (6).

Eventually, on the upper echelon, the best response of each supplier can be achieved by optimizing that supplier's sub-model while the strategies of all the other players are known. In other words, by fixing the strategies of the retailers, the manufacturer, and the remaining suppliers, we apply the KKT optimality conditions of each supplier. Since the sub-model of each supplier is convex regarding its decision variables, the best responses of the suppliers can be achieved through KKT conditions. By replacing $v_{j s}$ according to Eq. (9), the benefit function of each supplier only depends on $F_{j s}$. Thus, it is sufficient to derive the Lagrange equation and complementarity slackness with respect to $F_{j s}$ for each supplier as follows: 


$$
\begin{aligned}
& L_{s_{s}}\left(F_{j s}=\sum_{j=1}^{J} \sum_{s=1}^{S} F_{j s}\left(Q_{j}-\eta_{j s} F_{j s}+\sum_{s=1 / s}^{s} \theta_{j \underline{s}} F_{j \underline{s}}\right)\right. \\
& -\sum_{j=1}^{J} \sum_{s=1}^{S} C s_{j s}\left(Q_{j}-\eta_{j s} F_{j s}+\sum_{s=1 / s}^{S} \theta_{j \underline{s}} F_{j \underline{s}}\right) \\
& -\mu_{j}\left(\sum_{s=1}^{S}\left(Q_{j}-\eta_{j s} F_{j s}+\sum_{s=1 / s}^{S} \theta_{j \underline{s}} F_{j \underline{s}}\right)-Q_{j}\right), \\
& \frac{\partial L_{S_{s}}\left(F_{j s}\right)}{\partial F_{j s}}=\left(Q_{j}-\eta_{j s} F_{j s}+\sum_{s=1 / s}^{S} \theta_{j \underline{s}} F_{j \underline{s}}\right) \\
& -\eta_{j s}\left(F_{j s}-C s_{j s}\right)-\mu_{j}\left(-\eta_{j s}\right. \\
& \left.+(s-1) \theta_{j s}\right)=0, \\
& \mu_{j}\left(\sum_{s=1}^{S}\left(Q_{j}-\eta_{j s} F_{j s}+\sum_{s=1 / s}^{S} \theta_{j s} F_{j s}\right)-Q_{j}\right)=0 .
\end{aligned}
$$

Note that the KKT system of equations for each supplier depends not only on the manufacturer's and the retailers' strategies, but also on the other competitive supplier's raw material prices. $\mu_{j}$ is the Lagrange multiplier, which might be either positive or negative. Since the NCP formulation handles only positive variables and constraints in the standard form of $g(x) \geq 0$, we set $\mu_{j}=\mu_{j}^{+}-\mu_{j}^{-}$and replace Eq. (24) with Eqs. (25) and (26):

$$
\begin{aligned}
& \mu_{j}^{+}\left(\sum_{s=1}^{S}\left(Q_{j}-\eta_{j s} F_{j s}+\sum_{s=1 / s}^{S} \theta_{j s} F_{j s}\right)-Q_{j}\right)=0 \\
& \mu_{j}^{-}\left(Q_{j}-\sum_{s=1}^{S}\left(Q_{j}-\eta_{j s} F_{j s}+\sum_{s=1 / s}^{S} \theta_{j s} F_{j s}\right)\right)=0 .
\end{aligned}
$$

The Nash equilibrium of the three-echelon supply chain game can be achieved by combining the optimality conditions of all the players in one system of equations. In order to solve such a system, we formulate it as an NCP for which commercial solvers exist. To form the NCP formulation, we use the optimality conditions of all the players, which have been discussed above. Therefore, the NCP formulation of the problem is as shown in Box I.

Since the convexity assumption holds for all players, the multi-echelon supply game of the current research has a unique Nash equilibrium point [42] which can be obtained by the NCP system. In order to solve the NCP, we code the equations system (Eq. (27)) in the GAMS 24.1.2 software and apply the commercial PATH 4.7 solver. PATH employs a generalization of Newton's method on a non-smooth reformulation of the complementarity problem.

\subsection{The iterative algorithm}

By increasing the dimension of the problem, NCP is not able to find a solution in a reasonable time. Thus, we propose a Jacobi type decomposition algorithm as an alternative approach to calculate the Nash equilibrium of the three-echelon competitive supply chain in large instances:

- Step 1: Choose an initial wholesale price for each product $\overline{\psi_{0}^{i}}$ and set the initial common production interval $\overline{T^{0}}=1$; the iteration number is $t=0$;

- Step 2: Given $\overline{\psi_{i}^{t}}$ and $\overline{T^{t}}$, calculate the optimal value of retail price $p_{i r}^{*}$ and marketing expenditure $m_{i r}^{*}$ for each retailer according to Eqs. (14) and (15). Then, set $\overline{p_{i r}^{t}}=p_{i r}^{*}, \overline{m_{i r}^{t}}=m_{i r}^{*}$;

- Step 3: Given $\overline{p_{i r}^{t}}$ and $\overline{m_{i r}^{t}}$, we calculate the demand $\overline{D_{i r}^{t}}$ for each product according to Eq. (1). Then, $\overline{Q_{j}^{t}}$ can be obtained through Eq. (6). Consequently, we can calculate the optimal value of raw materials' prices and the optimal quantity of the $j$ th raw material produced by each supplier $\overline{F_{j s}^{t}}=F_{j s}^{*}$ and $\overline{v_{j s}^{t}}=v_{j s}^{*}$, respectively;

- Step 4: Given ${\overline{D_{i r}^{t}}}_{F_{j s}}^{t}$, and $\overline{v_{j s}^{t}}$, the optimal value of the wholesale price for each product $\overline{\psi_{i}^{t}}=\psi_{i}^{*}$ and the optimal common production interval $\overline{T^{t}}=T^{*}$ can be calculated according to Eqs. (20) and (21);

- Step 5: Finally, for a small positive $\varepsilon$, if $\| \overline{\psi_{i}^{t}}-$ $\overline{\psi_{i}^{t-1}} \| \leq \varepsilon$ and $\left\|\overline{T^{t}}-\overline{T^{t-1}}\right\| \leq \varepsilon$, stop, otherwise set $t=\bar{t}+1$ and go to Step 2 .

It has been proved that if the above iterative algorithm converges, it converges to the Nash equilibrium point of the multi-echelon game [42]. Furthermore, when the sub-problems of all the supply chain members are convex, we have both the existence and the uniqueness characteristics of the Nash equilibrium point.

\section{Computational result}

In this section, we describe and discuss the application of the proposed game model for the problem of three-echelon competitive supply chain. The main parameters of the numerical example are set based on Naimi Sadigh et al. [39] and Esmaeili et al. [27]. Based on these previous works, it is assumed that for each product, we have $h_{i r}>h m_{i}$ and $A s_{i}>$ $A r_{i r}$. It means that the holding cost of each product for any retailer is greater than the manufacturer's holding cost, and the manufacturer's set-up cost is 


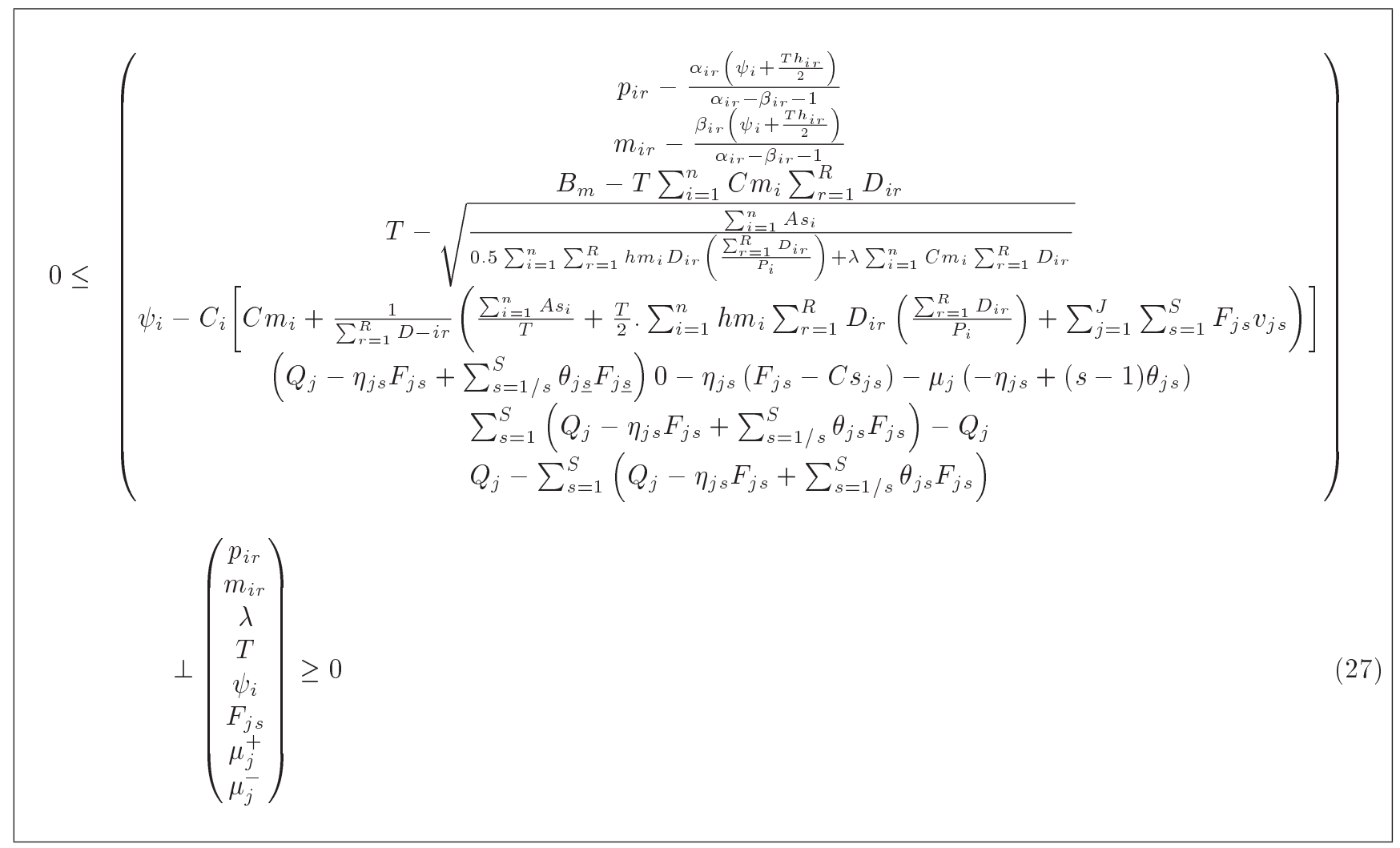

Box I

much higher than any ordering cost of the retailers. Finally, we carry out a sensitivity analysis on the main parameters of the game model and derive some managerial highlights.

\subsection{Numerical results}

Consider a supply chain consisting of four suppliers, one manufacturer, and three retailers, where the manufacturer produces four products from five raw materials provided by the suppliers. The parameters in sub-problems of the retailers, the manufacturer, and the suppliers are shown in Tables 3-5, respectively. We employed the proposed solution algorithm in this example and found that the algorithm converged after a few number of iterations during a reasonable time (less than 1 minute). The iterative algorithm is coded in MATLAB R2013a software. The values of the optimal strategies in the Nash equilibrium point of the GNEP supply chain model are then presented in Tables 6 and 7 .

The equilibrium retail prices and marketing expenditures along with the associated realized demand are reported in Table 6 for different products. The wholesale prices of each product are $\psi_{i}^{*}=56.46$, $\psi_{2}^{*}=58.14, \psi_{3}^{*}=61.05$, and $\psi_{4}^{*}=61.93$, and the values of the required raw materials are $Q_{1}^{*}=463.11$, $Q_{2}^{*}=227.52, Q_{3}^{*}=365.54, Q_{4}^{*}=328.68, Q_{5}^{*}=201.18$ for the manufacturer in the equilibrium of the whole
Table 3. Parameters in the retailers' echelon.

\begin{tabular}{|c|c|c|c|}
\hline \multirow{2}{*}{ Parameter } & \multicolumn{3}{|c|}{ Retailer } \\
\hline & 1 & 2 & 3 \\
\hline \multirow{4}{*}{$f_{i r}^{*} 10^{4}$} & 75 & 80 & 80 \\
\hline & 25 & 30 & 60 \\
\hline & 44 & 40 & 45 \\
\hline & 52 & 50 & 55 \\
\hline \multirow{4}{*}{$\alpha_{i r}$} & 1.8 & 1.7 & 1.6 \\
\hline & 1.9 & 1.6 & 1.7 \\
\hline & 2.15 & 2.1 & 2.2 \\
\hline & 1.95 & 2.0 & 1.8 \\
\hline \multirow{4}{*}{$\beta_{i r}$} & 0.15 & 0.20 & 0.10 \\
\hline & 0.40 & 0.30 & 0.20 \\
\hline & 0.50 & 0.70 & 0.60 \\
\hline & 0.25 & 0.40 & 0.20 \\
\hline \multirow{4}{*}{$A r_{i r}$} & 20 & 15 & 10 \\
\hline & 30 & 25 & 25 \\
\hline & 60 & 70 & 50 \\
\hline & 45 & 50 & 40 \\
\hline \multirow{4}{*}{$h_{i r}$} & 2 & 4 & 2 \\
\hline & 4 & 6 & 2 \\
\hline & 6 & 4 & 10 \\
\hline & 6 & 10 & 4 \\
\hline
\end{tabular}


Table 4. Parameters in the manufacturer's echelon.

\begin{tabular}{ccccccccccc}
\hline & \multicolumn{10}{c}{ Parameter } \\
\cline { 2 - 9 } Product & $\boldsymbol{C m}_{\boldsymbol{i}}$ & $\boldsymbol{A s _ { \boldsymbol { i } }}$ & $\boldsymbol{h m}_{\boldsymbol{i}}$ & $\boldsymbol{P}_{\boldsymbol{i}}$ & $\boldsymbol{u}_{\boldsymbol{1} \boldsymbol{i}}$ & $\boldsymbol{u}_{\boldsymbol{2} \boldsymbol{i}}$ & $\boldsymbol{u}_{\boldsymbol{3} \boldsymbol{i}}$ & $\boldsymbol{u}_{\boldsymbol{4} \boldsymbol{i}}$ & $\boldsymbol{u}_{\boldsymbol{5} \boldsymbol{i}}$ \\
\hline 1 & 2 & 140 & 1 & 10000 & 1 & 0 & 0.5 & 0.6 & 0.2 \\
2 & 3 & 180 & 0.5 & 9000 & 0 & 0.6 & 0.2 & 0.3 & 0.4 \\
3 & 4 & 430 & 0.6 & 8000 & 0 & 1 & 0.3 & 0.3 & 0 \\
4 & 5 & 160 & 0.9 & 9000 & 0.5 & 0.4 & 1 & 0 & 0.4 \\
\hline
\end{tabular}

Table 5. Parameters in the suppliers' echelon.

\begin{tabular}{ccccc}
\hline \multirow{4}{*}{ Parameter } & \multicolumn{4}{c}{ Raw material } \\
\cline { 2 - 5 } & $\mathbf{1}$ & $\mathbf{2}$ & $\mathbf{3}$ & $\mathbf{4}$ \\
\hline$\eta_{j s}$ & 18 & 17 & 12 & 20 \\
& 19 & 18 & 17 & 19 \\
& 11 & 21 & 10 & 19 \\
& 20 & 13 & 10 & 15 \\
Cs $_{j s}$ & 22 & 22 & 20 & 26 \\
& 0.5 & 1 & 0.7 & 0.4 \\
& 0.6 & 0.25 & 0.35 & 0.5 \\
& 0.35 & 0.5 & 0.45 & 0.5 \\
& 0.3 & 0.2 & 0.25 & 0.4 \\
$\theta_{j s}$ & 0.25 & 0.55 & 0.25 & 0.1 \\
& 0.01 & 0.04 & 0.05 & 0.07 \\
& 0.02 & 0.05 & 0.10 & 0.07 \\
& 0.03 & 0.04 & 0.01 & 0.05 \\
& 0.04 & 0.07 & 0.08 & 0.06 \\
& 0.02 & 0.05 & 0.07 & 0.10 \\
\hline
\end{tabular}

Table 6. Decision variables of three retailers.

\begin{tabular}{cccc}
\hline \multirow{2}{*}{ Variables } & \multicolumn{3}{c}{ Retailer } \\
\cline { 2 - 4 }$p_{\text {ir }}^{*}$ & 184.15 & 260.22 & 212.79 \\
& 297.22 & 470.69 & 231.81 \\
& 301.53 & 425.89 & 407.86 \\
& 256.41 & 373.73 & 246.02 \\
& 94.55 & 124.22 & 195.31 \\
$D_{\text {ir }}$ & 26.16 & 60.88 & 110.81 \\
& 17.21 & 38.64 & 13.73 \\
& 24.99 & 20.10 & 52.96 \\
& & & \\
& 15.34 & 30.61 & 13.30 \\
$a_{i r}$ & 62.67 & 88.25 & 27.27 \\
& 70.12 & 141.96 & 111.23 \\
& 32.87 & 74.75 & 27.33 \\
\hline
\end{tabular}

game. Table 7 shows the decision variables of the four suppliers for the five raw materials, which include the raw materials' prices and quantities. Finally, net profit of each supply chain member (player) is stated in Table 8.
Table 7. Decision variables of four suppliers.

\begin{tabular}{ccccc}
\hline \multirow{2}{*}{ Variables } & \multicolumn{4}{c}{ Raw material } \\
\cline { 2 - 5 } & $\mathbf{1}$ & $\mathbf{2}$ & $\mathbf{3}$ & $\mathbf{4}$ \\
\hline \multirow{4}{*}{$F_{j s}$} & 19.93 & 20.88 & 26.39 & 18.50 \\
& 9.31 & 9.45 & 9.83 & 9.22 \\
& 22.67 & 14.81 & 24.44 & 15.72 \\
& 14.15 & 18.50 & 22.28 & 16.92 \\
& 6.86 & 7.00 & 7.30 & 6.05 \\
& 107.87 & 110.88 & 148.79 & 95.57 \\
& 52.70 & 59.25 & 61.70 & 53.87 \\
& 117.79 & 56.14 & 123.18 & 68.42 \\
& 49.79 & 91.64 & 108.76 & 78.48 \\
& 51.64 & 48.42 & 56.30 & 44.81 \\
\hline
\end{tabular}

\subsection{Sensitivity analysis and Managerial insights}

In this subsection, we perform a sensitivity analysis on the main parameters of the game model and draw some important managerial insights.

The less the self-price elasticity $\left(\alpha_{i r}\right)$ of a product, the higher the demand will be gained by the retailer for that product. For example, according to Table 6, the demand of first product is much more than that of the third product for retailer 3 , because $\alpha_{13}<\alpha_{33}$. In fact, the less $\alpha_{i r}$ implies that any change in price has a relatively small effect on the quantity of the demanded product, which means that the product will be sold in a less competitive market. In contrast, there is higher competition when $\alpha_{i r}$ is large for a product. Besides, the reason why retailers 2 and 3 earn more than twice the profit of retailer 1 is the less self-price elasticity $\left(\alpha_{i r}\right)$ they have for almost all products. To analyze the influence of $\alpha_{i r}$, we change all $\alpha_{i r} s$ in the interval $\left[0.85 \alpha_{i r}, 1.2 \alpha_{i r}\right]$ and show its effect on the mean of retail prices and wholesale prices for four products, and the mean of raw material prices for five raw materials, respectively, in Figure 2(a) and (b). Figure 2(c) depicts the variation of supply chain members' benefits based on the change in self-price elasticity.

On the other side, if marketing expenditure has much significant impact on the demand of one product in the market, we choose a larger $\beta_{i r}$ for that product of the retailer, which causes higher marketing expenditure for the corresponding retailer and, consequently, results in more demand of the product gained by that retailer, the manufacturer, and the associated suppliers. On the contrary, when $\beta_{i r}$ is low, marketing has negligible influence on the quantity of the demanded product. Therefore, the retailer expends less money for marketing of that product, which leads to less market demand. In Figure 3, we increase $\beta_{i r}$ in the interval 
Table 8. Objective function values for supply chain members.

\begin{tabular}{|c|c|c|c|c|c|c|c|}
\hline \multicolumn{3}{|c|}{ Retailer } & \multirow{2}{*}{ Manufact urer } & \multicolumn{4}{|c|}{ Supplier } \\
\hline 1 & 2 & 3 & & 1 & 2 & 3 & 4 \\
\hline 19449.66 & 48501.53 & 50858.35 & 15378.82 & 6214.92 & 5542.30 & 10155.10 & 4804.17 \\
\hline
\end{tabular}

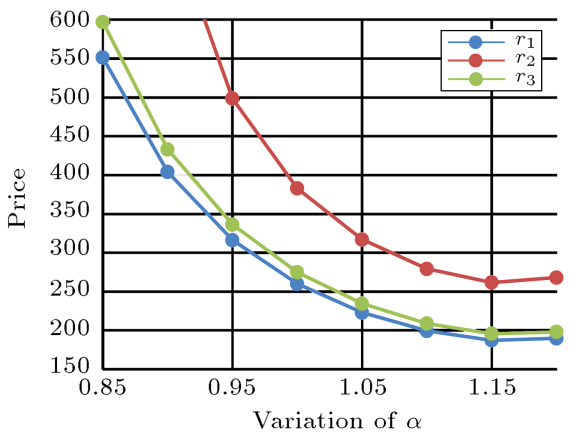

(a) The retailers' mean price

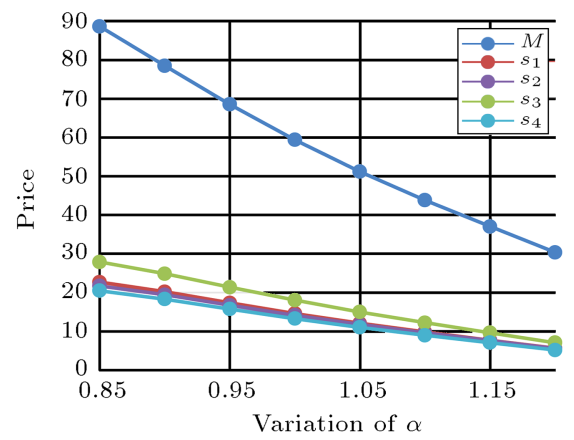

(b) The mean price of manufacturer and suppliers

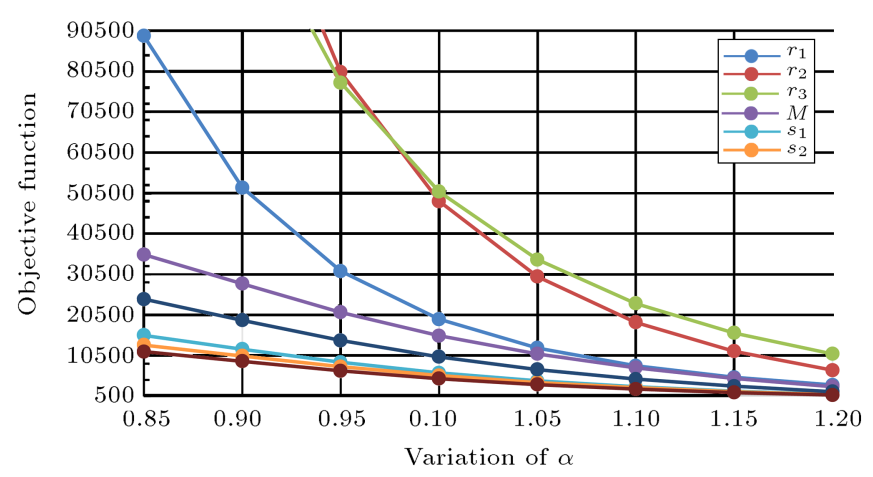

(c) The benefit of retailers, manufacturer and suppliers

Figure 2. The effect of price elasticity of retailers' demand $(\alpha)$.

$\left[0.85 \beta_{i r}, 1.2 \beta_{i r}\right]$, which results in increasing prices and, consequently, benefits of all supply chain members.

Through Tables 6 and 7 , one can easily see that the higher wholesale price the manufacturer proposes for any product, the higher will be the retail price of that product. Subsequently, the relevant suppliers will sell the respective raw materials with higher prices. In other words, in a less competitive market, the retailer, the manufacturer, and the respective suppliers are able to propose higher prices. In contrast, when there is higher competition, they need to offer lower prices to achieve demand and remain in the market. In order to investigate the influence of wholesale price, we have altered the coefficient $C_{i}$ of the breakeven price in the interval $[1.2,1.9]$ and found that the mean retail price and mean raw material price have consequently been increased (Figure 4(a) and (b)). As we expected, only the benefit of the manufacturer has raised by increase in $C_{i}$, but the benefit of the retailers and the suppliers has been reduced (Figure 4(c)).

The required quantity of raw materials from manufacturer acts as the total market demand for all the respective suppliers. Then, the suppliers compete with each other to gain more market share of this required quantity. The self-price elasticity of raw materials $\left(\eta_{j s}\right)$ depends on several factors such as reputation of suppliers in the respective raw material's market. So, less $\eta_{j s}$ means that the supplier has much reputed brand. In fact, the manufacturer accepts to pay much money to purchase the required materials from the much reputed suppliers. Therefore, the suppliers with less $\eta_{j s}$ will sell the raw materials with higher price. Furthermore, these suppliers may gain more demand and produce higher quantity of raw materials (i.e., less $\eta_{j s}$ goes to higher $v_{j s}$ ). For the example, as can be seen in Table 8, supplier 3 obtains about twice the profit of supplier 4, because it has low self-price elasticity factors in comparison with supplier 4 for all raw materials (see Table 5). In order to depict the influence of the parameter $\eta_{j s}$, we change this parameter in the interval $\left[0.7 \eta_{j s}, 1.4 \eta_{j s}\right]$. Figure 5 shows that the mean price of all supply chain members can be decreased by increasing selfprice elasticity of raw materials $\left(\eta_{j s}\right)$ and, consequently, all the members can benefit more from this price reduction. 


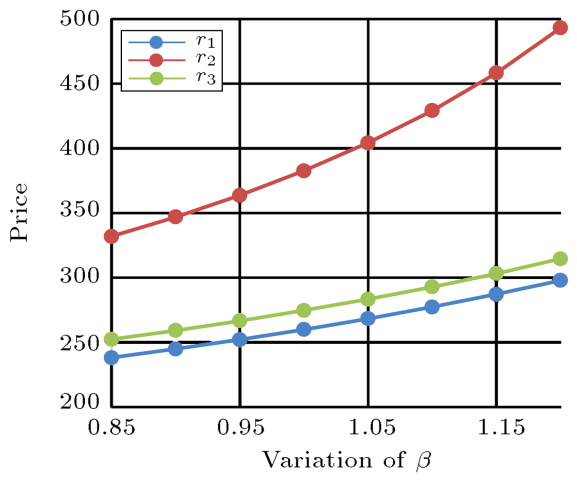

(a) The retailers' mean price

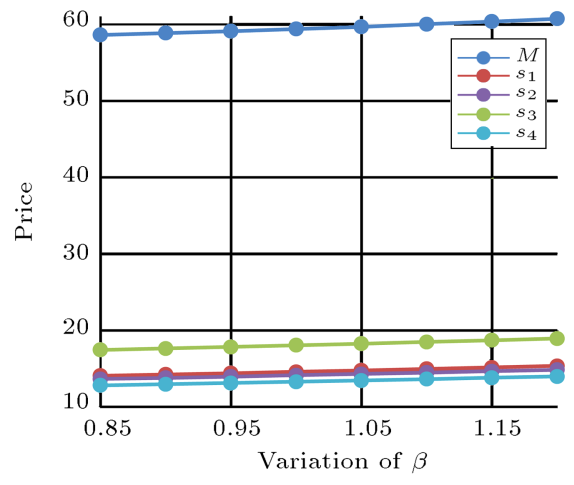

(b) The mean price of manufacturer and suppliers

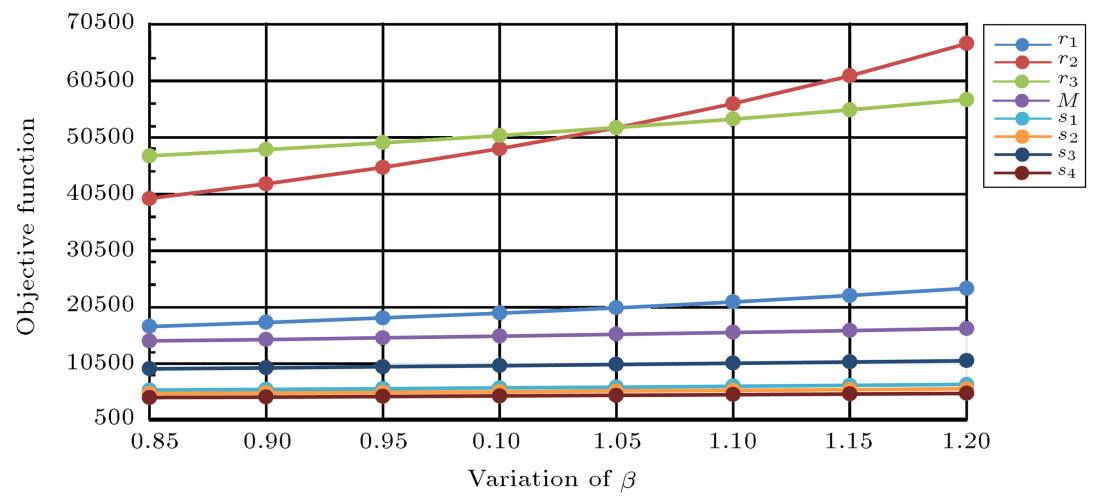

(c) The benefit of retailers, manufacturer and suppliers

Figure 3. The effect of marketing elasticity of retailers' demand $(\beta)$.

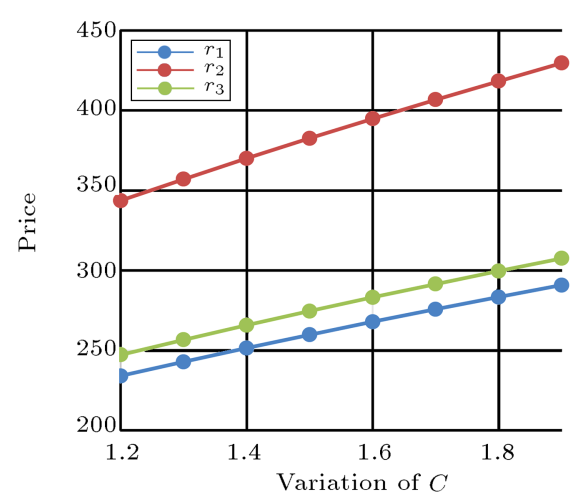

(a) The retailers' mean price

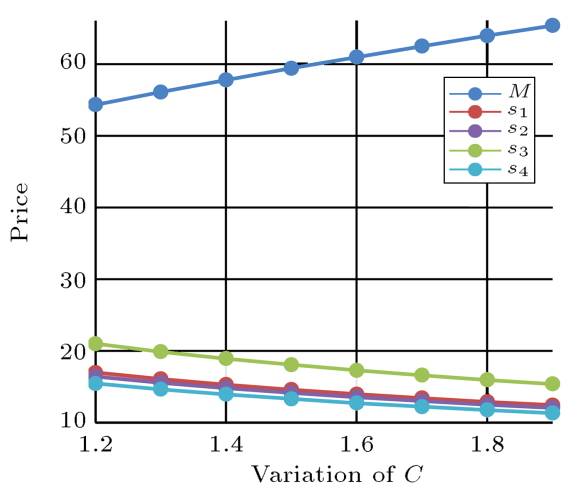

(b) The mean price of manufacturer and suppliers

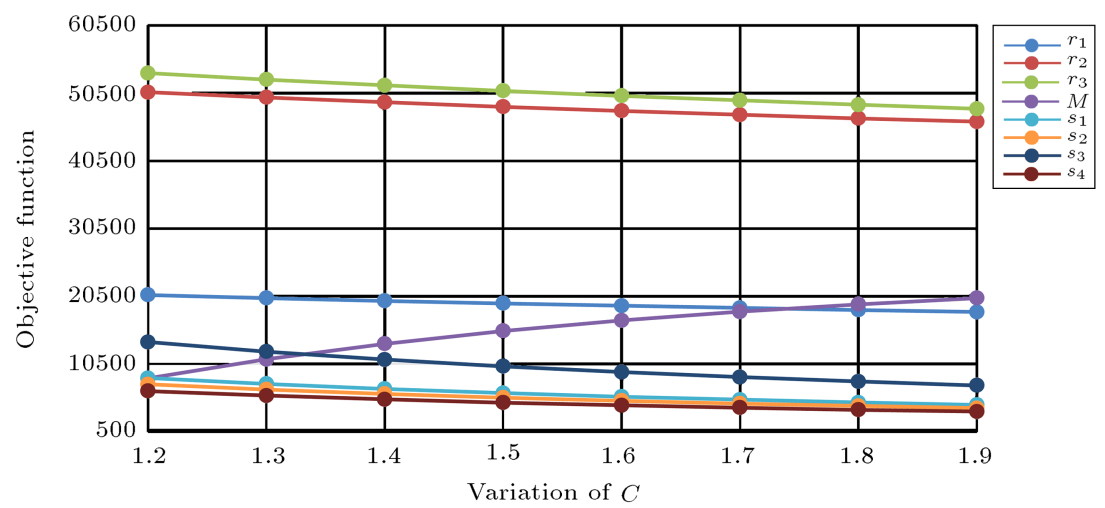

(c) The benefit of retailers, manufacturer and suppliers

Figure 4. The effect of manufacturer's unit cost coefficient $(C)$. 


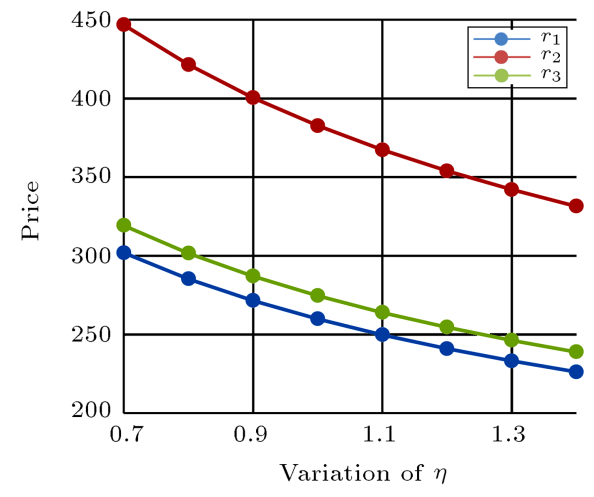

(a) The retailers' mean price

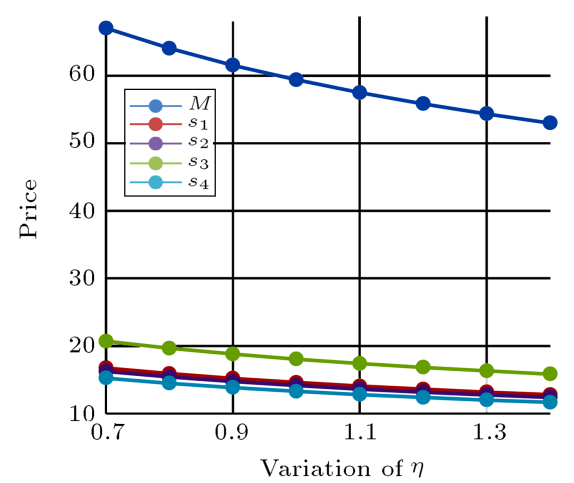

(b) The mean price of manufacturer and suppliers

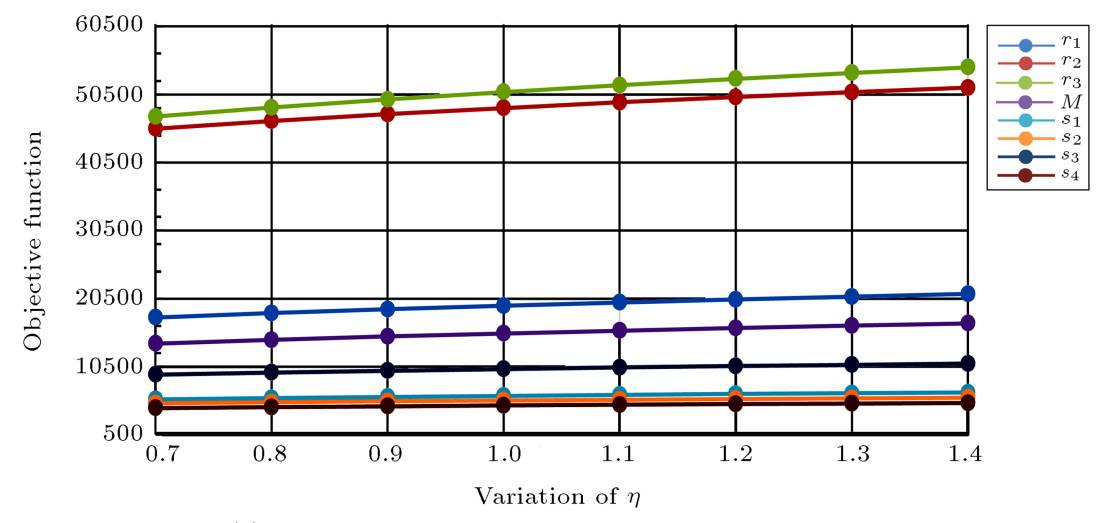

(c) The benefit of retailers, manufacturer and suppliers

Figure 5. The effect of suppliers' price elasticity $(\eta)$.

\section{Concluding remarks}

This paper investigated the coordination of pricing and marketing decisions in a multi-product decentralized supply chain with three echelons. The demand of each product is non-linearly influenced by the retail price as well as the marketing expenditure each retailer spends. In the upper echelon of the supply chain, there are multiple suppliers who compete on raw material prices, which then impact the wholesale price of the manufacturer and, consequently, the retail prices of different retailers. The coordination mechanism addressed in the current paper aims to align the objectives of the different supply chain participants with the whole supply chain's benefit. We modeled the problem as a non-cooperative Nash game in which all the players set their strategies simultaneously. Two solution approaches, including the NCP formulation and an iterative algorithm, were proposed to obtain the NASH equilibrium point of the game in instances with different sizes.

A numerical example was presented and a comprehensive sensitivity analysis was conducted on the main parameters of the model. The results show that if the retailers propose higher prices, then the manufacturer and respective suppliers sell their products with higher prices. In addition, self-price elasticity factor of retailers acts as the main factor in the realized demand and profit of the whole supply chain. The wholesale price of the manufacturer is influenced by his own prime cost, which is equal to breakeven price. The less prime cost he endures, the less will be the product retailing price as well as the respective raw materials prices. Moreover, the suppliers with less selfprice elasticity factor may be able to propose higher prices and supply more quantities for the manufacturer. As an immediate extension, it would be interesting to consider the competition among multiple products or multiple retailers. Other power structures, including Stackelberg and cooperative game, are also worth to be addressed.

\section{References}

1. Weng, Z.K. "Channel coordination and quantity discounts", Management Science, 41(9), pp. 1509-1522 (1995).

2. Yu, Y., Chu, F. and Chen, H. "A Stackelberg game and its improvement in a VMI system with a manufacturing vendor", European Journal of Operational Research, 192, pp. 929-948 (2009).

3. Ramdas, K. and Spekman, R.E. "Chain or shackles: understanding what drives supply-chain performance", Interfaces, 30(4), pp. 3-21 (2000). 
4. Fugate, B., Shahin, F. and Mentzer, J. "Supply chain management coordination mechanism", Journal of Business Logistics, 27(2), pp. 129-161 (2006).

5. Goyal, S.K. "A joint economic-lot-size model for purchase and vendor: A comment", Decision Sciences, 19, pp. 236-241 (1988).

6. Tersine, R.J. and Price, R.L. "Temporary price discounts and EOQ", Journal of Purchasing and Materials Management, 17(4), pp. 23-27 (1981).

7. Martin, G.E. "Note an EOQ model with a temporary sale price", International Journal of Production Economics, 37(2-3), pp. 241-243 (1994).

8. Abad P.L. "Optimal price and lot size when the supplier offers a temporary price reduction over an interval", Computers and Operations Research, 30(1), pp. 63-74 (2003).

9. Yu, Y., Liang, L. and Huang, G.Q. "Leader-follower game in vendor-managed inventory system with limited production capacity considering wholesale and retail prices", International Journal of Logistics: Research and Application, 9(4), pp. 335-350 (2006).

10. SeyedEsfahani, M.M., Biazaran, M. and Gharakhani, M. "A game theoretic approach to coordinate pricing and vertical co-op advertising in manufacturer- retailer supply chains", European Journal of Operational Research, 211(2), pp. 263-273 (2011).

11. Esmaeili, M. and Zeephongsekul, P. "Seller-buyer models of supply chain management with an asymmetric information structure", International Journal of Production Economics, 123(1), pp. 146-154 (2010).

12. Wu, C. and Zhao, Q. "An inventory model for deteriorating items with inventory-dependent and linear trend demand under trade credit", Scientia Iranica, $E$, 22(6), pp. 2558-2570 (2015).

13. Li, H. and You, T. "Capacity commitment and pricing for substitutable products under competition", Journal of Systems Science and Systems Engineering, 21(4), pp. 443-460 (2012).

14. Thonemann, U.W. and Bradley, J.R. "The effect of product variety on supply-chain performance", European Journal of Operational Research, 143(3), pp. 548556 (2002).

15. Song, J.S. and Xue, Z. "Demand management and inventory control for substitutable products", Technical report, Duke University, Durham, NC (2007).

16. Zhu, K. and Thonemann, U. "Coordination of pricing and inventory control across products", Naval Research Logistics, 56(2), pp. 175-190 (2009).

17. Dong, L., Kouvelis, P. and Tian, Z. "Dynamic pricing and inventory control of substitute products", Manufacturing \& Service Operations Management, 11(2), pp. 317-339 (2009).

18. Maihami, R. and Karimi, B. "Optimizing the pricing and replenishment policy for non-instantaneous deteriorating items with stochastic demand and promotional efforts", Computers \& Operations Research, 52, pp. 302-312 (2014).
19. Hsieh, C.C., Chang, Y.L. and Wu, C.H. "Competitive pricing and ordering decisions in a multiple-channel supply chain", International Journal of Production Economics, 154, pp. 156-165 (2014).

20. Karray, S. "Periodicity of pricing and marketing efforts in a distribution channel", European Journal of Operational Research, 228(3), pp. 635-647 (2013).

21. Kunter, M. "Coordination via cost and revenue sharing in manufacturer- retailer channels", European Journal of Operational Research, 216(2), pp. 477-486 (2012).

22. Zhang, J., Xie, J. and Chen, B. "Cooperative advertising with bilateral participation", Decision Sciences, 44(1), pp. 193-203 (2013).

23. Aust, G. and Buscher, U. "Game theoretic analysis of pricing and vertical cooperative advertising of a retailer-duopoly with a common manufacturer", Central European Journal of Operational Research (2014). Doi 10.1007/s10100-014-0338-7.

24. Sayadi, M.K. and Makui, A. "Optimal advertising decisions for promoting retail and online channels in a dynamic framework", International Transactions in Operational Research, 21, pp. 777-796 (2014).

25. Tsao, Y.-C. and Sheen, G.-J. "Effects of promotion cost sharing policy with the sales learning curve on supply chain coordination", Computers \& Operations Research, 39(8), pp. 1872-1878 (2012).

26. Yang, J., Xie, J., Deng, X. and Xiong, H. "Cooperative advertising in a distribution channel with fairness concerns", European Journal of Operational Research, 227(2), pp. 401-407 (2013).

27. Esmaeili, M., Aryanezhad, M.-B. and Zeephongeskul, P. "A game theory approach in seller-buyer supply chain", European Journal of Operational Research, 191(2), pp. 442-448 (2009).

28. Yue, J., Austin, J., Huang, Z. and Chen, B. "Pricing and advertisement in a manufacturer-retailer supply chain", European Journal of Operational Research, 231(2), pp. 492-502 (2013).

29. Basar, T. and Olsder, G.J. Dynamic Noncooperative Game Theory, Academic Press (1982).

30. Hafezalkotob, A. and Makui, A. "Network design of a decentralized distribution supply chain: Analysis of non-cooperative equilibrium vs. coordination with discount or buyback mechanism", Scientia Iranica, E, 21(3), pp. 988-1006 (2014).

31. Qin, Y., Tang, H. and Guo, C. "Channel coordination and volume discounts with price-sensitive demand", International Journal of Production Economics, 105(1), pp. 43-53 (2007).

32. Caldentey, R. and Wein, L. "Analysis of a decentralized production-inventory system", Manufacturing and Service Operations Management, 5, pp. 1-17 (2003).

33. Dumrongsiri, A., Fan, M., Jain, A. and Moinzadeh, K. "A supply chain model with direct and retail channels", European Journal of Operational Research, 187(3), pp. 691-718 (2008). 
34. Cai, G.G., Zhang, Z.G. and Zhang, M. "Game theoretical perspectives on dual channel supply chain competition with price discounts and pricing schemes", International Journal of Production Economics, 117(1), pp. 80-96 (2009).

35. Yue, D. and You, F. "Game-theoretic modeling and optimization of multi-echelon supply chain design and operation under Stackelberg game and market equilibrium", Computers \& Chemical Engineering, 71, pp. 347-361 (2014).

36. Hoseininia, M., Seyyed Esfahani, M.M., Didehvar, F. and Haghi, A. "Inventory competition in a multi channel distribution system: The Nash and Stackelberg game", Scientia Iranica, E, 20(3), pp. 846-854 (2013).

37. Aust, G. and Buscher, U. "Cooperative advertising models in supply chain management: A review", European Journal of Operation Research, 234(1), pp. 1-14 (2014).

38. Naimi Sadigh, A., Chaharsooghi, S.K. and Sheikhmohammady, M. "A game theoretic approach to coordination of pricing, advertising, and inventory decisions in a competitive supply chain", Journal of Industrial and Management Optimization, 12(1), pp. 337-355 (2016).

39. Naimi Sadigh, A., Mozafari, M. and Karimi, B. "Manufacturer-retailer supply chain coordination: A bi-level programming approach", Advances in Engineering Software, 45(1), pp. 144-152 (2012).

40. Huang, Y., Huang, G.Q. and Newman, S.T. "Coordinating pricing and inventory decisions in a multi-level supply chain: A game-theoretic approach", Transportation Research Part E, 47, pp. 115-129 (2011).

41. Shi, N., Zhou, S., Wang, F., Xu, S. and Xiong, S. "Horizontal cooperation and information sharing between suppliers in the manufacturer-supplier triad", International Journal of Production Research, 52(15), pp. $4526-4547$ (2013).

42. Facchinei, F. and Kanzow, C. "Generalized Nash equilibrium problems", 4OR, 5, pp. 173-210 (2007).

43. Naimi Sadigh, A., Karimi, B. and Zanjirani Farahani, R. "A game theoretic approach for two echelon supply chains with continuous depletion", International Journal of Management Science and Engineering Management, 6(6), pp. 408-412 (2011).

\section{Appendix A}

Proposition 1. The retailers' benefit functions are pseudo-concave regarding the retail prices and the marketing expenditures.

Proof. In order to prove the pseudo-concavity of the retailers' objective functions, we use the approach presented by Naimi Sadigh et al. [43] due to the similarity of the retailers' objectives with the buyer's objective in their model. Since the benefit function of each retailer is separable, we can replace Eq. (19) of their paper $\left(A=\psi+M+A_{b} / Q\right)$ with $A=$ $\psi_{i}+m_{i r}+\frac{T h_{i r}}{2}$ in our paper. Thus, we easily apply the same proof. On the other hand, the second derivative of the objective function $\Pi_{R_{r}}$ can be calculated as follows:

$$
\frac{\partial^{2} \Pi R_{r}\left(p_{i r}^{*}, m_{i r}^{*}\right)}{\partial m_{i r}^{2}}=\frac{\alpha_{i r}-\beta_{i r}-1}{\left(1-\alpha_{i r}\right) m^{*}}<0 .
$$

Since Eq. (A.1) is negative, the objective function is concave and the proof is completed.

\section{Appendix B}

Proposition 2: The sub-model of the manufacturer is a convex program with respect to its decision variables.

Proof. Consider $f$ as the objective function of the manufacturer; we can form the Hessian matrix of $-f$ as follows:

$$
\begin{aligned}
H\left(-\Pi_{M}\left(\psi_{i}, T\right)\right) & =\left[\begin{array}{cc}
-\frac{\partial^{2} \Pi_{M}\left(\psi_{i}, T\right)}{\partial \psi_{i}^{2}} & -\frac{\partial^{2} \Pi_{M}\left(\psi_{i}, T\right)}{\partial \psi_{i} \partial T} \\
\frac{-\partial^{2} \Pi_{M}\left(\psi_{i}, T\right)}{\partial \psi_{i} \partial T} & \frac{-\partial^{2} \Pi_{M}\left(\psi_{i}, T\right)}{\partial T^{2}}
\end{array}\right] \\
& =\left[\begin{array}{cc}
0 & 0 \\
0 & \frac{2 \sum_{i=1}^{n} A s_{i}}{T^{3}}
\end{array}\right] .
\end{aligned}
$$

Eq. (B.1) is a positive semi-definite one if for every non-zero vector $\left(\psi_{i}, T\right)$, Eq. (B.2) holds:

$$
\left(\psi_{i}, T\right) \cdot\left[H\left(-\Pi_{M}\left(\psi_{i}, T\right)\right)\right] \cdot\left(\psi_{i}, T\right)^{T} \leq 0
$$

Here, $\left(\psi_{i}, T\right)^{T}$ denotes the transpose of $\left(\psi_{i}, T\right)$. Therefore, we have:

$$
\left[\begin{array}{ll}
0 & \frac{2 \sum_{i=1}^{n} A s_{i}}{T^{2}}
\end{array}\right] \cdot\left[\begin{array}{c}
\psi_{i} \\
T
\end{array}\right]=\frac{2 \sum_{i=1}^{n} A s_{i}}{T} \geq 0 .
$$

Thus, $-f$ is positive semi-definite and $f$ is concave. Furthermore, all the constraints of the manufacturer's model are linear. Then, the manufacturer has a convex set and the proof is completed.

\section{Biographies}

Ali Naimi Sadigh obtained his BS, MS, and PhD degrees in Industrial Engineering from K.N. Toosi University of Technology, Amirkabir University of Technology, and Tarbiat Modares University, respectively. His research interests include pricing, revenue management, game theory, supply chain, and optimization. He has published several papers in the reputable journals.

Seyed Kamal Chaharsooghi is Associate Professor of Industrial Engineering in the Department of In- 
dustrial Engineering at Tarbiat Modares University, Tehran, Iran. His research interests include manufacturing systems, supply chain management, information systems, strategic management, international marketing strategy, and systems theory. His work has appeared in European Journal of Operational Research, International Journal of Advanced Manufacturing Technology, Scientia Iranica, Modares Journal of Engineering, Amirkabir Journal of Science and Technology, and International Journal of Engineering Science. He obtained his PhD from Hull University, England.

Majid Sheikhmohammady is currently a faculty member in the Department of Industrial Engineering at Tarbiat Modares University. He holds $\mathrm{PhD}$ in
Systems Design Engineering from the University of Waterloo, Canada. As a Post-doctoral fellow, he was the manager of a research project entitled "Systems Engineering Approaches to Brownfield Redevelopment Projects". His primary research interests lie in the analysis of decisions as the intersection of mathematics, engineering, and social sciences. His applications of game theory and related formal techniques include problems in conflict resolution, coalition formation, group decision and negotiation, fair division, and environmental management. He has pioneered the development of a methodology to model and analyze multilateral negotiations from a Systems Engineering perspective. More specifically, the new methodology, called EMMN, predicts the outcome of multilateral negotiations. 